Author(s): Lindroos, Jeanette \& Savin, Hele

Title: $\quad$ Formation kinetics of copper-related light-induced degradation in crystalline silicon

Year: $\quad 2014$

Version: Final published version

Please cite the original version:

Lindroos, Jeanette \& Savin, Hele. 2014. Formation kinetics of copper-related light-induced degradation in crystalline silicon. Journal of Applied Physics. P. 5. 1089-7550 (electronic). DOI: 10.1063/1.4904197.

Note: $\quad$ Copyright 2014 American Institute of Physics. This article may be downloaded for personal use only. Any other use requires prior permission of the author and the American Institute of Physics.

http://scitation.aip.org/content/aip/journal/jap

All material supplied via Aaltodoc is protected by copyright and other intellectual property rights, and duplication or sale of all or part of any of the repository collections is not permitted, except that material may be duplicated by you for your research use or educational purposes in electronic or print form. You must obtain permission for any other use. Electronic or print copies may not be offered, whether for sale or otherwise to anyone who is not an authorised user. 


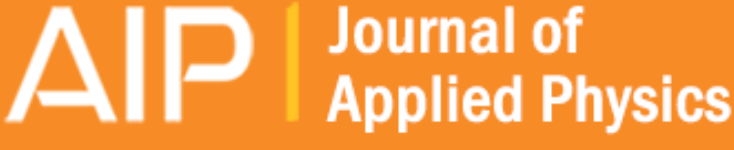

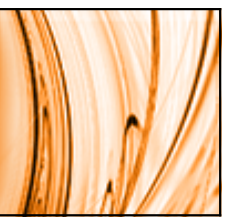

\section{Formation kinetics of copper-related light-induced degradation in crystalline silicon}

J. Lindroos and H. Savin

Citation: Journal of Applied Physics 116, 234901 (2014); doi: 10.1063/1.4904197

View online: http://dx.doi.org/10.1063/1.4904197

View Table of Contents: http://scitation.aip.org/content/aip/journal/jap/116/23?ver=pdfcov

Published by the AIP Publishing

\section{Articles you may be interested in}

Preventing light-induced degradation in multicrystalline silicon

J. Appl. Phys. 115, 154902 (2014); 10.1063/1.4871404

Light-induced degradation in compensated p- and n-type Czochralski silicon wafers

J. Appl. Phys. 109, 053718 (2011); 10.1063/1.3552302

Kinetics of creation and of thermal annealing of light-induced defects in microcrystalline silicon solar cells J. Appl. Phys. 103, 054504 (2008); 10.1063/1.2844282

Electronic characterization and effects of light-induced degradation on hydrogenated nanocrystalline silicon Appl. Phys. Lett. 88, 071920 (2006); 10.1063/1.2175480

You don't

still use this

cell phone

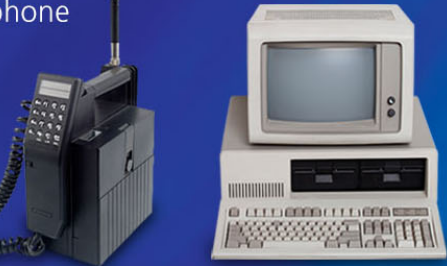

Why are you still using an AFM designed in the 80 's?
It is time to upgrade your AFM Minimum $\$ 20,000$ trade-in discount for purchases before August 31st

Asylum Research is today's technology leader in AFM 


\title{
Formation kinetics of copper-related light-induced degradation in crystalline silicon
}

\author{
J. Lindroos ${ }^{\text {a) }}$ and H. Savin \\ Department of Micro and Nanosciences, Aalto University, Tietotie 3, 02150 Espoo, Finland
}

(Received 18 August 2014; accepted 2 December 2014; published online 16 December 2014)

\begin{abstract}
Light-induced degradation (LID) is a deleterious effect in crystalline silicon, which is considered to originate from recombination-active boron-oxygen complexes and/or copper-related defects. Although LID in both cases appears as a fast initial decay followed by a second slower degradation, we show that the time constant of copper-related degradation increases with increasing boron concentration in contrast to boron-oxygen LID. Temperature-dependent analysis reveals that the defect formation is limited by copper diffusion. Finally, interface defect density measurements confirm that copper-related LID is dominated by recombination in the wafer bulk. (C) 2014 AIP Publishing LLC. [http://dx.doi.org/10.1063/1.4904197]
\end{abstract}

\section{INTRODUCTION}

Improving the solar cell efficiency is the most effective way to cut down on silicon solar cell module costs. ${ }^{1}$ Therefore, it is imperative to identify the defect responsible for light-induced degradation (LID), accounting for 1-2\% efficiency decrease in crystalline silicon solar cells during one day of illumination. ${ }^{2}$ During the past four decades, most studies have pointed to a highly recombination-active boronoxygen complex (BO-LID), ${ }^{3,4}$ but the defect composition remains unclear. ${ }^{5}$ The defect is dissociated at $200{ }^{\circ} \mathrm{C}^{6}$, and the degradation can be prevented by simultaneous illumination and annealing. ${ }^{7}$

Copper is a common $3 d$ transition metal impurity in industrial silicon solar cells, which under illumination also causes lifetime degradation (Cu-LID).$^{8-10}$ Hence, crystalline silicon can suffer from BO-LID, Cu-LID, or a combination of both degradation effects. In Cu-LID, illumination is proposed to enable the growth of recombination-active copper precipitates $\left(\mathrm{Cu}_{3} \mathrm{Si}\right)$ by lowering the repulsion between $\mathrm{Cu}_{i}^{+}$ and $\mathrm{Cu}_{3} \mathrm{Si}^{\mathrm{O} /+}{ }^{11}$ but the formation kinetics of $\mathrm{Cu}-\mathrm{LID}$ remain unclear. As opposed to BO-LID, no defect dissociation has been observed to occur at $200^{\circ} \mathrm{C}$ in intentionally contaminated $\mathrm{Cz}-\mathrm{Si}^{12}$ However, the effect of $\mathrm{Cu}-\mathrm{LID}$ has been shown to decrease after the deposition of a large negative surface, attracting $\mathrm{Cu}_{i}^{+}$from the bulk towards the sample surface. ${ }^{13,14}$

During illumination of oxidized copper-contaminated $\mathrm{Si}$, lifetime degradation has been measured together with a significant interface defect density increase, suggesting that surface passivation degradation is solely responsible for copper-related LID. ${ }^{15} \mathrm{Cu}$-LID has since been proven to be a bulk effect, ${ }^{16}$ but it is uncertain whether copper also affects surface passivation during illumination in corona-charged oxidized Si. To determine the surface passivation stability in copper-contaminated $\mathrm{Si}$, we examine the $\mathrm{Si} / \mathrm{SiO}_{2}$ interface properties during illumination as a function of corona charge density and copper concentration.

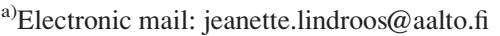

Although the activation energy of BO-LID is established as $0.23 \pm 0.02 \mathrm{eV}$ for the fast initial degradation and $0.475 \pm 0.035 \mathrm{eV}$ for slow degradation, ${ }^{17}$ the activation energy of $\mathrm{Cu}-\mathrm{LID}$ is yet to be determined. In order to better understand the formation kinetics of $\mathrm{Cu}$-LID, we illuminate copper-contaminated silicon and measure the degradation time constant at varying temperatures to obtain the degradation activation energy.

\section{EXPERIMENTAL}

The experiments were performed on a $\langle 100\rangle$-oriented, 100-mm, boron-doped FZ (Float Zone) and electronic-grade $\mathrm{Cz}$ (Czochralski) silicon. The resistivity of the $287-\mu \mathrm{m}$-thick low-oxygen FZ wafers was $3 \Omega \mathrm{cm}$. The $400-\mu \mathrm{m}$ thick $3.4-3.9 \Omega \mathrm{cm}$ (low-res) and 525- $\mu \mathrm{m}$ thick $18-24 \Omega \mathrm{cm}$ (highres) $\mathrm{Cz}-\mathrm{Si}$ wafers contained oxygen concentrations of 14 ppma and 11-13 ppma, respectively.

After standard RCA cleaning and a HF dip, the wafers were passivated with a $16-\mathrm{nm}$ thermal oxide during $40 \mathrm{~min}$ of dry oxidation followed by $20 \mathrm{~min}$ of annealing at $900{ }^{\circ} \mathrm{C}$ in $\mathrm{N}_{2}$ atmosphere. Some wafers were kept as oxidized reference wafers, while the rest were intentionally copper contaminated by spinning 0.5 and $1 \mathrm{ppm}(\mathrm{w} / \mathrm{v})$ of copper solution onto the front side of the wafers. The copper contamination was diffused into the wafer bulk during a $20 \mathrm{~min}$ anneal at $800^{\circ} \mathrm{C}$ in $\mathrm{N}_{2}$ atmosphere followed by air cooling. The surface oxide keeps copper at these concentrations as interstitials in the bulk even after slow cooling. ${ }^{18}$

Finally, an external corona charge was deposited onto both sides of the wafer in the dark. A positive charge $\left(+0.26 \mu \mathrm{C} / \mathrm{cm}^{2}\right)$ was deposited to keep $\mathrm{Cu}_{i}^{+}$in the wafer bulk, while a large negative charge $\left(-0.79\right.$ and $\left.-1.58 \mu \mathrm{C} / \mathrm{cm}^{2}\right)$ was used to drive $\mathrm{Cu}_{i}^{+}$out of the bulk towards the wafer surface at $\mathrm{RT}$ in the dark for at least $12 \mathrm{~h} .{ }^{11}$ Corresponding corona charge densities were also deposited onto the clean reference wafers. The wafers were then cut into halves and divided into three groups for measurements.

Group 1 samples were first annealed on a hot plate in the dark at $210 \pm 10^{\circ} \mathrm{C}$ for $2 \mathrm{~min}$. Since annealing reduced 
the corona charge density, $+0.05 \mu \mathrm{C} / \mathrm{cm}^{2}$ was added to both sides of each sample. Group 2 samples were kept in the dark at RT. Both sample groups were illuminated with a 1-sun halogen lamp on a hot plate at temperatures $(27-80) \pm 3{ }^{\circ} \mathrm{C}$. Between illuminations, the effective minority carrier recombination lifetime was monitored by Quasi-Steady State Photoconductance Decay (QSSPC) measurements with a Sinton WCT-120 tool at $22 \pm 2{ }^{\circ} \mathrm{C}$ at an injection level of $10 \%$ below the doping density. The low injection level was chosen to ensure that the measured lifetime was dominated by Shockley-Read-Hall recombination. ${ }^{19,20}$ After illumination, the corona charge of the low-resistivity samples was compensated with the same amount of opposite corona charge, and the $\mathrm{Si} / \mathrm{SiO}_{2}$ interface defect density was immediately measured by the non-contact Corona Oxide Characterization of Semiconductor $(\mathrm{COCOS})^{21}$ method with a Semilab PV 2000 lifetime scanner.

In group 3, the reference samples were annealed at 210 $\pm 10^{\circ} \mathrm{C}$ for $2 \mathrm{~min}$ and recharged with $+0.05 \mu \mathrm{C} / \mathrm{cm}^{2}$. Some contaminated samples were also annealed at $210 \pm 10^{\circ} \mathrm{C}$ for $1000 \mathrm{~min}$, after which $+0.2 \mu \mathrm{C} / \mathrm{cm}^{2}$ of corona charge was added. The group 3 samples were not subjected to illumination, but their corona charge was compensated, and the oxide interface defect density was measured with COCOS.

\section{RESULTS AND DISCUSSION}

\section{A. Dark anneal}

Since the boron-oxygen defect dissociates at $200{ }^{\circ} \mathrm{C},{ }^{6}$ samples are usually annealed in the dark prior to illumination to recover any degradation formed during sample preparation. Figure 1 presents the effective lifetime as a function of dark annealing time in positively corona-charged coppercontaminated (0.5 and $1 \mathrm{ppm})$ high- and low-resistivity $\mathrm{Cz}-\mathrm{Si}$. During $1000 \mathrm{~min}$ of dark annealing, the lifetime decreases in all samples. A lifetime decrease is expected, as increased recombination has previously been observed in copper-contaminated $\mathrm{FZ}^{8}$ and $\mathrm{Cz}-\mathrm{Si}^{16}$ during dark annealing at $210^{\circ} \mathrm{C}$. However, after only a short anneal of $2 \mathrm{~min}$, a lifetime increase is observed in the low-res samples. This

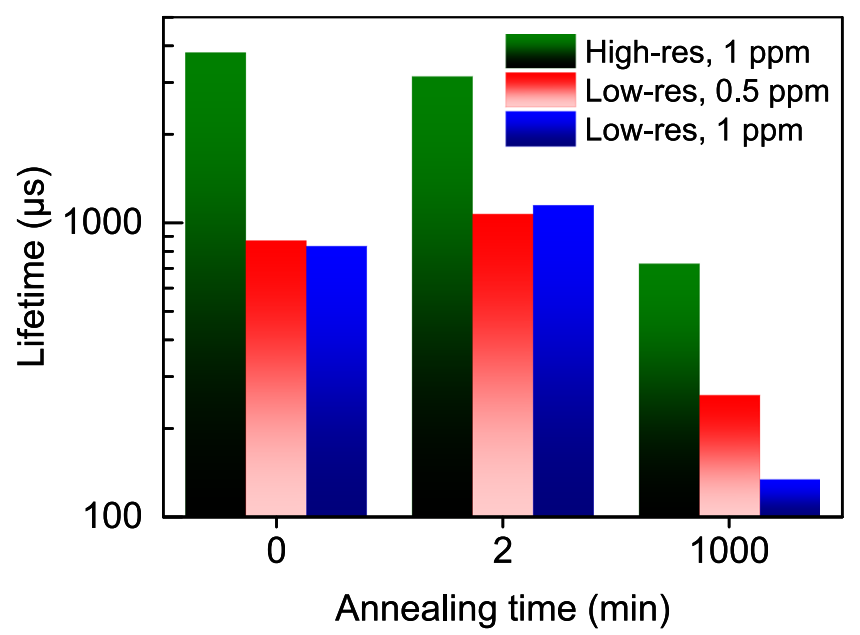

FIG. 1. Effective lifetime as a function of dark annealing time at $210^{\circ} \mathrm{C}$ in contaminated ( 0.5 and $1 \mathrm{ppm})$ high- and low-resistivity $\mathrm{Cz}-\mathrm{Si}$. increase is probably caused by the dissociation of boronoxygen defects formed during sample preparation.

Any copper diffusion towards the surface during the anneal does not cause significant recombination in the $\mathrm{Si}$ / $\mathrm{SiO}_{2}$ interface, as the interface defect density $D_{i t}$ increases only from 1.6 to $1.9 \times 10^{11} \mathrm{~cm}^{-2} \mathrm{eV}^{-1}$ during the long-term anneal in the 1-ppm low-res sample. Therefore, bulk-related degradation dominates in all samples during dark annealing. Since higher concentrations of copper ( $8 \mathrm{ppm})$ has been shown to decrease the lifetime during short-term annealing, ${ }^{16}$ we can conclude that the lifetime behavior during dark annealing depends on copper concentration, sample resistivity, and annealing time.

\section{B. Degradation kinetics}

Figure 2 presents the effective lifetime as a function of illumination time and temperature in positively coronacharged clean (Ref.) and contaminated (0.5 and $1 \mathrm{ppm})$ lowand high-res $\mathrm{Cz}-\mathrm{Si}$. All samples belong to group 1, which were annealed at $210^{\circ} \mathrm{C}$ for $2 \mathrm{~min}$ before illumination. Figure 2(a) also shows the stable effective lifetime in the clean low-res FZ-Si wafer, which ensures stable surface passivation in the clean reference $\mathrm{Cz}-\mathrm{Si}$ samples during illumination. Both low- and high-res reference samples show typical BO-related degradation with a fast initial exponential decay followed by a second slower asymptotic degradation. The degradation time constant $\tau_{\operatorname{deg} 1}$ for fast and slow

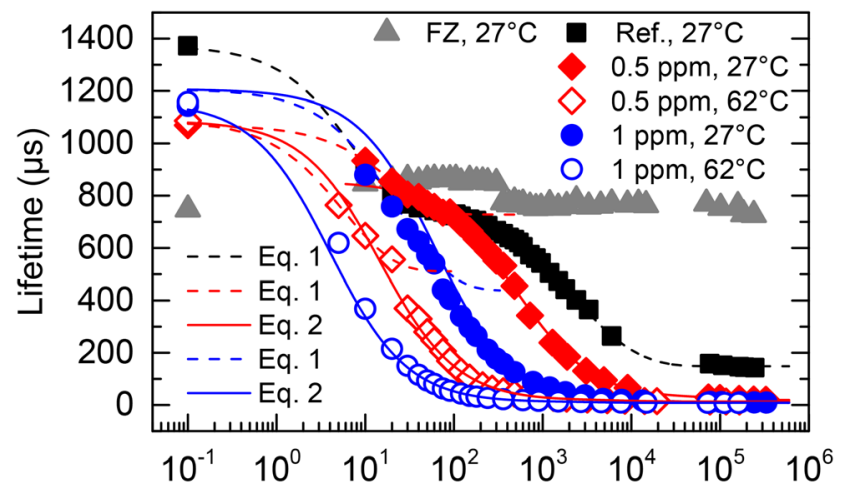

a)

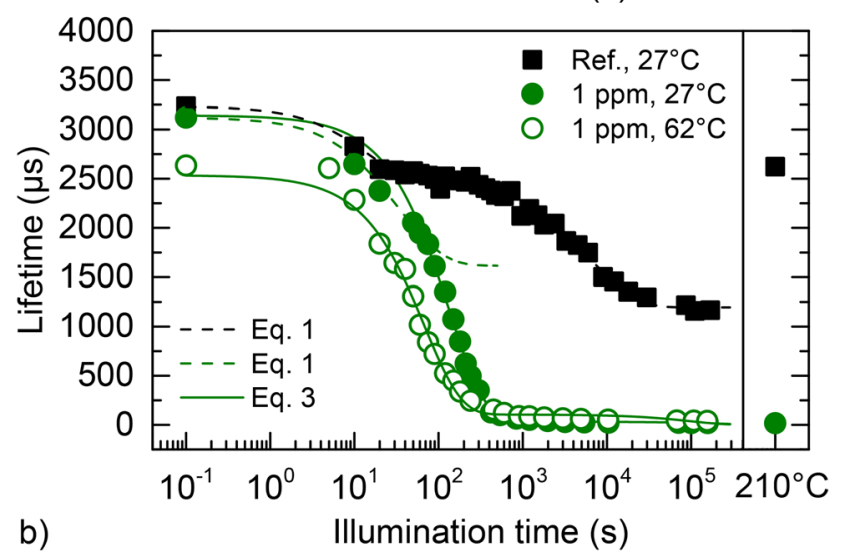

FIG. 2. Effective lifetime as a function of illumination time and temperature in (a) clean (Ref.) and contaminated ( 0.5 and $1 \mathrm{ppm})$ low-resistivity Cz- and $\mathrm{FZ}-\mathrm{Si}$, and (b) clean (Ref.) and contaminated (1 ppm) high-resistivity $\mathrm{Cz}-\mathrm{Si}$ with a final dark anneal at $210^{\circ} \mathrm{C}$. 
BO-LID can be determined by fitting each part of the lifetime decay data with ${ }^{2}$

$$
N(t)=\frac{1}{\tau(t)}-\frac{1}{\tau_{0}}=\left(\frac{1}{\tau_{\text {fin }}}-\frac{1}{\tau_{0}}\right)\left(1-\exp \left(-\frac{t}{\tau_{\mathrm{deg} 1}}\right)\right),
$$

where $N(t)$ is the normalized density of generated defects, $\tau_{0}$ is the initial lifetime, and $\tau_{\text {fin }}$ is the final saturated lifetime. Although the high-res material shows typical BO-LID, the final lifetime stabilizes at $1166 \mu \mathrm{s}$. The stable lifetime is two to three times higher than expected from literature, ${ }^{22}$ which might be explained by the superior surface passivation of corona-charged thermal oxide compared to standard silicon nitride. A final anneal at $210^{\circ} \mathrm{C}$ recovers the BO-related degradation, as known from literature. ${ }^{6}$

The contaminated $\mathrm{Cz}-\mathrm{Si}$ samples show a very similar lifetime decrease of a fast initial decay and a second slower degradation at $27^{\circ} \mathrm{C}$. However, the second degradation is both faster and more severe in the intentionally contaminated samples compared to the reference samples. Another difference is that the lifetime does not recover during the final $210^{\circ} \mathrm{C}$ anneal, indicating that $\mathrm{Cu}-\mathrm{LID}$ dominates the degradation in the intentionally contaminated Cz-Si samples. ${ }^{10,12,13}$

From the saturated normalized defect density, the copper concentrations are estimated as $1.1 \times 10^{14} \mathrm{~cm}^{-2}$ in the 0.5 -ppm and $1.6 \times 10^{14} \mathrm{~cm}^{-2}$ in the 1-ppm-contaminated low-res samples, respectively. ${ }^{23}$ In the 1 -ppm high-res samples, the copper concentrations is estimated as $1.2 \times 10^{14} \mathrm{~cm}^{-2}$, which is lower than the low-res sample density due to a thicker wafer. All copper concentrations are similar regardless of wafer doping and degradation time constant, as $\mathrm{Cu}$-LID dominates the degradation.

The copper-related degradation time constant is known to decrease with increasing copper concentration, ${ }^{10}$ but $\mathrm{Cu}$ LID kinetics are also clearly dependent on the boron concentration in Fig. 2. Since the degradation time constant increases with increasing boron concentration, two different models are used to fit $\mathrm{Cu}$-LID. In the intentionally contaminated low-res samples in Fig. 2(a), the fast initial degradation can be fitted by Eq. (1), but the second slower degradation requires a double exponential fit of

$$
\begin{aligned}
N(t) & =\frac{1}{\tau(t)}-\frac{1}{\tau_{0}} \\
& =a \cdot\left(1-\exp \left(-\frac{t}{\tau_{\mathrm{deg} 2}}\right)\right)+b \cdot\left(1-\exp \left(-\frac{t}{\tau_{\mathrm{deg} 3}}\right)\right),
\end{aligned}
$$

where $\tau_{\operatorname{deg} 2}$ is the degradation time constant for slow degradation and $\tau_{\mathrm{deg} 3}$ is the degradation time constant for very slow degradation towards the end of illumination. In the intentionally contaminated high-res samples in Fig. 2(b), the fast initial degradation can again be fitted by Eq. (1). However, the second degradation is much more rapid than in the low-res samples, requiring a double direct exponential fit of

$$
\tau(t)=c \cdot \exp \left(-\frac{t}{\tau_{\mathrm{deg} 4}}\right)+d \cdot \exp \left(-\frac{t}{\tau_{\mathrm{deg} 5}}\right),
$$

where $\tau_{\text {deg } 4}$ is the degradation time constant for slow degradation and $\tau_{\text {deg} 5}$ is the degradation time constant for very slow degradation towards the end of illumination.

\section{Surface passivation stability}

Although the surface passivation of thermal oxide and positive corona charge stays stable during illumination in clean $\mathrm{FZ}$ and $\mathrm{Cz}-\mathrm{Si}$ as shown in Fig. 2, surface passivation stability cannot be guaranteed in intentionally coppercontaminated samples. Figure 3 presents the effective lifetime and the interface defect density $D_{i t}$ of reference and contaminated low-res $\mathrm{Cz}-\mathrm{Si}$ as a function of deposited corona charge density before and after 1-sun illumination. The clean reference samples were annealed at $210^{\circ} \mathrm{C}$ before illumination, while the contaminated samples were stored in the dark.

Although thermal oxidation effectively minimizes dangling bonds by a low $D_{i t}$ value of $3.6 \times 10^{10} \mathrm{~cm}^{-2} \mathrm{eV}^{-1}$, the field effect of the built-in oxide charge is not high enough to prevent minority carrier surface recombination, resulting in an initial lifetime of $128 \mu \mathrm{s}$ in reference $\mathrm{Cz}-\mathrm{Si}\left(0 \mu \mathrm{C} / \mathrm{cm}^{2}\right)$. Adding a positive corona charge $+0.26 \mu \mathrm{C} / \mathrm{cm}^{2}$ improves the field-effect passivation significantly, increasing the lifetime to $1372 \mu \mathrm{s}$ but also slightly increasing $D_{i t}$. Adding $-0.79 \mu \mathrm{C} / \mathrm{cm}^{2}$ of corona charge causes majority charge accumulation, which also improves the field-effect passivation, but not to the same extent as the positive charge. The initial lifetime difference between +0.26 and $-0.79 \mu \mathrm{C} / \mathrm{cm}^{2}$ can be explained by the field-effect difference, as the interface defect densities are similar.

A similar trend can be seen in the contaminated low-res samples. Adding some positive $\left(+0.26 \mu \mathrm{C} / \mathrm{cm}^{2}\right)$ or negative $\left(-0.79 \mu \mathrm{C} / \mathrm{cm}^{2}\right)$ corona charge affects the initial lifetime only
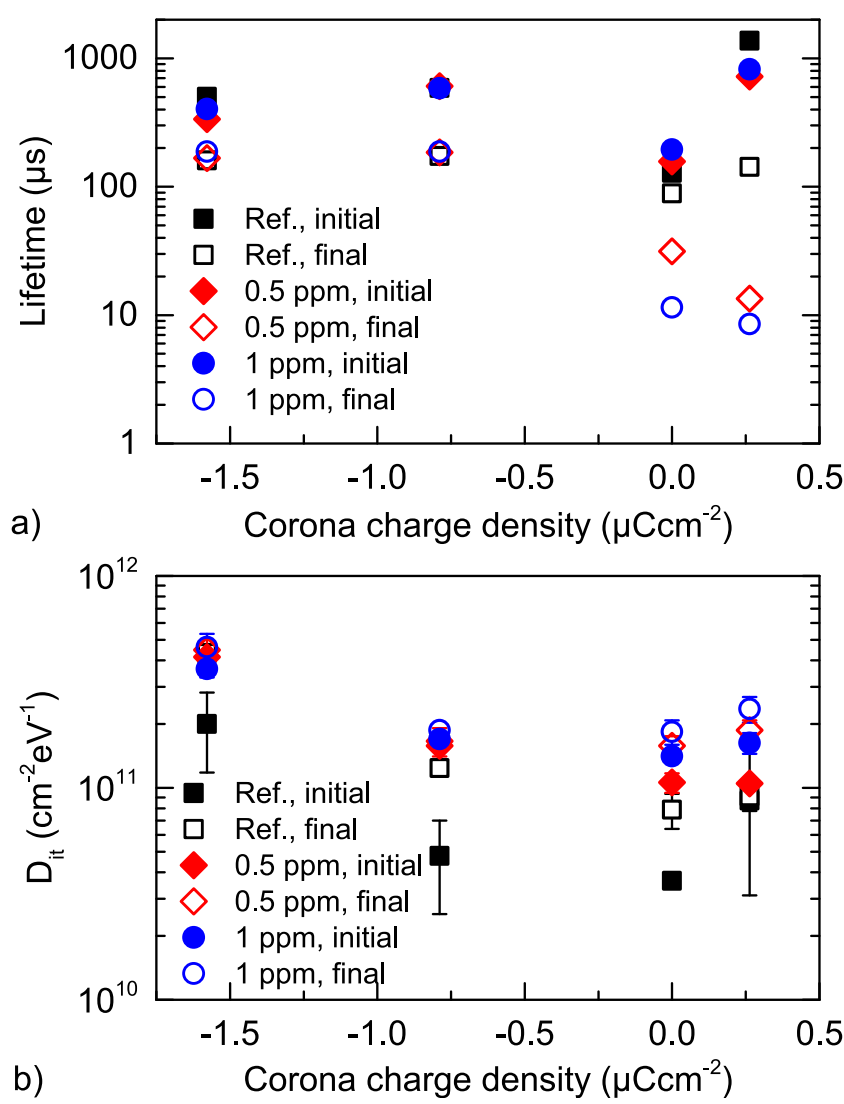

FIG. 3. (a) Effective lifetime and (b) interface defect density before (initial) and after (final) illumination as a function of surface corona charge density. 
through the field effect, not the interface defect density. However, the $D_{i t}$ level is determined by the contamination level, as $D_{i t}$ increases with increasing copper concentration. Increasing the negative charge to $-1.58 \mu \mathrm{C} / \mathrm{cm}^{2}$ causes a clear $D_{i t}$ increase in both the reference and contaminated samples, which could be caused by charge-induced impurity accumulation in the interface or even by partial oxide breakdown.

1 -sun illumination causes lifetime degradation and interface defect density increase in all samples, including the clean references. In the contaminated samples, some copper is expected to accumulate in the oxide interface during illumination, increasing the interface defect density and reducing surface passivation. ${ }^{15}$ During $\sim 2.5 \mathrm{~W} / \mathrm{cm}^{2}$ illumination, Boehringer et al. ${ }^{15}$ have measured a $5 \times 10^{11} \mathrm{~cm}^{-2} \mathrm{eV}^{-1} D_{\text {it }}$ increase accompanied by a $1 \mathrm{~ms}$ lifetime decrease in oxidized $5.5-10.5 \Omega \mathrm{cm} \mathrm{Cz-Si}$ with $4 \times 10^{12} \mathrm{Cu}$ atoms $/ \mathrm{cm}^{2}$. However, Figure 3(b) shows only a $4 \times 10^{10} \mathrm{~cm}^{-2} \mathrm{eV}^{-1}$ increase in the interface defect density after illumination in the 1-ppm-contaminated low-res sample $\left(6.4 \times 10^{12} \mathrm{~cm}^{-2}\right)$ with no added corona charge.

A similar $D_{i t}$ increase is also measured in the bare clean reference sample. This reference increase could be caused by light-induced accumulation of unintentional impurities in the interface or by UV degradation ${ }^{24,25}$ of the oxide. As the FZ lifetime is stable during illumination in Fig. 2(a), the lightinduced $D_{i t}$ increase does not significantly affect the reference surface passivation. Therefore, such a small $D_{i t}$ increase cannot explain the severe lifetime degradation measured in contaminated samples with and without corona charge.

With a negative surface charges $(-0.79$ and $-1.58 \mu \mathrm{C} / \mathrm{cm}^{2}$ ), the final lifetime stabilizes at the same level in the reference and the contaminated samples, regardless of $D_{i t}$. These final lifetimes also equal the degraded lifetime in the positively charged reference sample. Hence, the negative surface charge completely prevents $\mathrm{Cu}$-LID formation, leaving only BO-LID in the contaminated $\mathrm{Cz}$-Si samples.

\section{Temperature dependence of degradation}

The activation energy for boron-oxygen LID has been established as $0.23 \pm 0.02 \mathrm{eV}$ for the fast initial degradation and $0.475 \pm 0.035 \mathrm{eV}$ for slow degradation. ${ }^{17}$ The activation energies $E_{a}$ are independent of boron or oxygen concentrations, but the doping concentration is known to affect the pre-exponential $\kappa_{0}$ in $^{17}$

$$
R(T)=\frac{1}{\tau_{\operatorname{deg}}(T)}=\kappa_{0} \cdot \exp \left(-\frac{E_{a}}{k_{B} T}\right),
$$

where $R$ is the defect generation rate, $\tau_{\mathrm{deg}}$ is the degradation time constant, $k_{B}$ is the Boltzmann constant, and $T$ is the illumination temperature.

Figure 4 presents the defect generation rate $R$ of the second slow degradation as a function of illumination temperature in clean (Ref.) and contaminated (1 ppm) low- and high-res Cz-Si. In reference low-res samples, the defect generation rate of the slow degradation is obtained by fitting the lifetime degradation at each temperature with a single exponential decay using Eq. (1). Fitting the $\tau_{\operatorname{deg} 1}$ values with

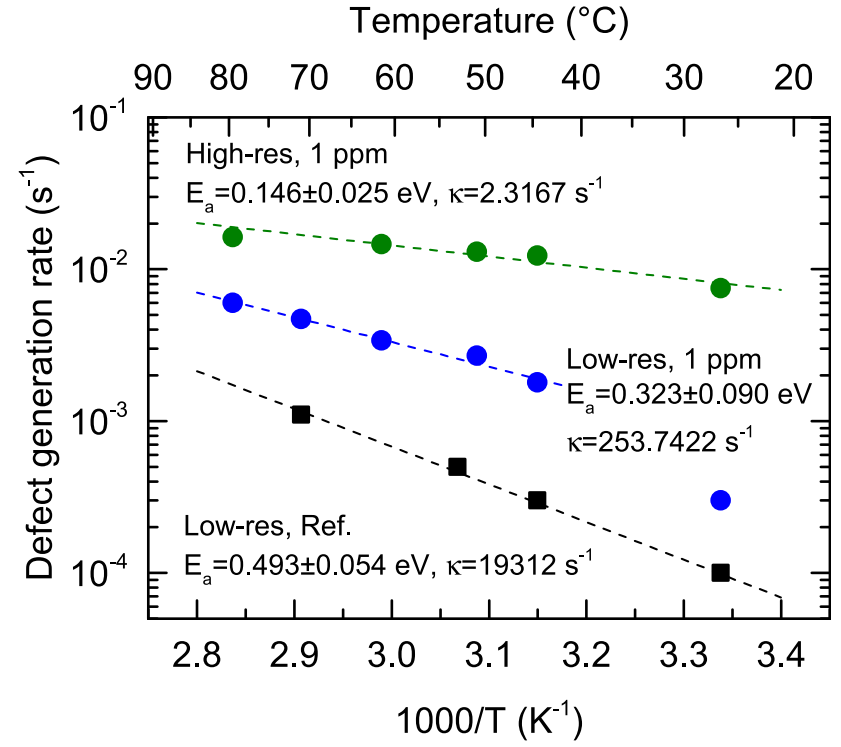

FIG. 4. Defect generation rate as a function of illumination temperature in clean (Ref.) and contaminated (1 ppm) low- and high-resistivity Cz-Si.

Eq. (4) results in the activation energy of $0.493 \pm 0.054 \mathrm{eV}$, which is within the error margins of the literature value ${ }^{17}$ for slow degradation in clean Cz-Si.

In the contaminated low-res samples, the second lifetime degradation is fitted with a two exponential decay using Eq. (2), of which the faster exponential $\tau_{\operatorname{deg} 2}$ reflects the defect generation rate of the slow degradation. Fitting the defect generation rate points at all temperatures except $27^{\circ} \mathrm{C}$ with Eq. (4) yields the activation energy of $0.323 \pm 0.090 \mathrm{eV}$. The lifetime degradation in the high-res samples is fitted with the direct exponential decay $\tau_{\operatorname{deg} 4}$ using Eq. (3), resulting in the activation energy of $0.146 \pm 0.025 \mathrm{eV}$.

The activation energy results in the contaminated samples are clearly much lower than that of slow BO-LID. In the contaminated samples, the activation energy also decreases with decreasing boron concentration, while the activation energy of BO-LID is known to be independent of the doping concentration. ${ }^{17}$ Therefore, BO-LID and Cu-LID appear to be formed during different reactions.

What is the formation reaction of Cu-LID? The obtained activation energies are low and clearly dependent of the doping level. Copper is known to form weak $\mathrm{CuB}$ pairs with the dissociation energy of $0.61 \mathrm{eV},{ }^{26,27}$ rendering $\mathrm{Cu}_{i}^{+}$diffusivity dependent on the wafer boron concentration. ${ }^{27}$ Annealing dissociates $\mathrm{CuB}$ pairs; thus, lowering the effective copper diffusion barrier. The higher the boron concentration, the higher temperature is needed to fully dissociate all $\mathrm{CuB}$ pairs and to achieve diffusion conditions of intrinsic $\mathrm{Si}$, where the activation energy of copper diffusivity is $0.18 \pm 0.01 \mathrm{eV} .^{27}$

The measured activation energy in the contaminated highres sample is very low $(0.146 \pm 0.025 \mathrm{eV})$, suggesting that the degradation is limited by the diffusivity of copper. Illuminating the sample during annealing might further dissociate $\mathrm{CuB}$ pairs, reducing the temperature required for intrinsic-like copper diffusion in the high-res material to near RT. In the low-res sample, the data point at $27^{\circ} \mathrm{C}$ is a clear outlier due to the high $\mathrm{CuB}$ concentration. Increasing the 
temperature dissociates $\mathrm{CuB}$ pairs and reduces the copper diffusion barrier, but intrinsic-like copper diffusion conditions are still not achieved at $80^{\circ} \mathrm{C}$. Consequently, a higher activation energy of $0.323 \pm 0.090 \mathrm{eV}$ is measured in the low-res sample.

The measured activation energies appear to reflect copper diffusivity instead of the formation of Cu-LID. Uncertainties in the activation energies are partly caused by lifetime data fitting discrepancies, but mainly by the nonconstant energy barrier of copper diffusivity in the temperature range of $27-80^{\circ} \mathrm{C}$. Since the experiment resulted in the activation energy of copper diffusivity, the activation energy of $\mathrm{Cu}$-LID remains unknown. The reason might be that $\mathrm{Cu}$-LID formation is faster than $\mathrm{Cu}_{i}^{+}$diffusion, regardless of the magnitude of the Cu-LID activation energy, making copper diffusion the limiting reaction in $\mathrm{Cu}$-LID formation. This copper diffusion limitation might also explain the slower $\mathrm{Cu}$-LID measured in Ga-doped $\mathrm{Cz}-\mathrm{Si},{ }^{28}$ as $\mathrm{CuGa}$ pairs have a higher dissociation energy $(0.7 \mathrm{eV})^{26}$ compared to $\mathrm{CuB}$ pairs.

\section{CONCLUSION}

High- and low-resistivity Cz-Si was intentionally contaminated with copper and subjected to 1-sun illumination at $27-80^{\circ} \mathrm{C}$. A fast initial decay and a second slower asymptotic degradation were observed similar to BO-LID, but the degradation kinetics depended on both the copper and the boron concentrations. The degradation time constant increased with increasing boron concentration and decreasing copper concentration. Since the lifetime degradation was both faster and more severe than in clean reference, and no recovery occurred during the final $210^{\circ} \mathrm{C}$ dark anneal, the measured degradation was identified as copperrelated LID.

Illumination increased slightly the interface defect density, regardless of sample copper concentration. As the final degraded lifetime was not limited by the interface defect density increase, the measured degradation was dominated by defect formation in the wafer bulk. The activation energy of the BO-related lifetime degradation was measured as $0.493 \pm 0.054 \mathrm{eV}$, which corresponds to previous literature data. ${ }^{17}$ In the contaminated low-res samples, the activation energy of $0.323 \pm 0.090 \mathrm{eV}$ was obtained, while the high-res samples yielded $0.146 \pm 0.025 \mathrm{eV}$. The activation energies were low and determined to reflect the diffusion barrier of $\mathrm{Cu}_{i}^{+}$, making copper diffusion the limiting reaction of $\mathrm{Cu}$-LID formation.

Although both BO-LID and Cu-LID were formed by fast and slow degradation, the defect formation kinetics clearly differed in the two degradation reactions. In Cu-LID, the degradation time constant increased with increasing boron concentration, while it has been shown to decrease in BO-LID. BO-LID was recoverable at $200^{\circ} \mathrm{C}$, but no recovery occurred in intentionally contaminated Si. Finally, the activation energy in the contaminated samples increased with increasing doping density, while the BO-LID activation energy has shown no dependency on the sample boron concentration.

\section{ACKNOWLEDGMENTS}

We acknowledge A. Haarahiltunen for copper diffusion modeling. This research was performed at the Micronova Nanofabrication Centre of Aalto University. The research leading to these results has received funding from the European Research Council under the European Union's Seventh Framework Programme (FP7/2007-2013)/ERC Grant Agreement $n^{\circ}$ [307315]. J.L. acknowledges the support of the Finnish Cultural Foundation, the Finnish Society of Electronics Engineers, and the Swedish Academy of Engineering Sciences in Finland (STViF).

${ }^{1}$ D. M. Powell, M. T. Winkler, H. J. Choi, C. B. Simmons, D. Berney Needleman, and T. Buonassisi, Energy Environ. Sci. 5, 5874 (2012).

${ }^{2}$ J. Schmidt, K. Bothe, and R. Hezel, in Proceedings of the 29th IEEE Photovoltaic Specialists Conference, New Orleans, LA, USA, 19-24 May 2002 (IEEE, 2002), pp. 178-181.

${ }^{3}$ J. Schmidt, A. G. Aberle, and R. Hezel, in Proceedings of the 26th IEEE Photovoltaic Specialists Conference, Anaheim, CA, USA, September 30-October 3, 1997 (IEEE, 1997), pp. 13-18.

${ }^{4}$ S. W. Glunz, S. Rein, W. Warta, J. Knobloch, and W. Wettling, Sol. Energy Mater. Sol. C 65, 219 (2001).

${ }^{5}$ V. V. Voronkov and R. Falster, Solid State Phenom. 205-206, 3 (2013).

${ }^{6} \mathrm{H}$. Fischer and W. Pschunder, in Proceedings of the 10th IEEE Photovoltaic Specialists Conference, Palo Alto, CA, USA, 13-15 November 1973 (IEEE, 1973), pp. 404-411.

${ }^{7}$ A. Herguth, G. Schubert, M. Kaes, and G. Hahn, in Proceedings of the 4th IEEE World Conference on PVEC, Waikoloa, HI, USA, May 7-12, 2006 (IEEE, 2006), pp. 940-943.

${ }^{8}$ D. Ramappa, Appl. Phys. Lett. 76, 3756 (2000).

${ }^{9}$ A. Belayachi, T. Heiser, J. P. Schunck, and A. Kempf, Appl. Phys. A 80, 201 (2005).

${ }^{10}$ H. Savin, M. Yli-Koski, and A. Haarahiltunen, Appl. Phys. Lett. 95, 152111 (2009).

${ }^{11}$ H. Väinölä, M. Yli-Koski, A. Haarahiltunen, and J. Sinkkonen, J. Electrochem. Soc. 150, G790 (2003).

${ }^{12}$ Y. Boulfrad, J. Lindroos, A. Inglese, M. Yli-Koski, and H. Savin, Energy Procedia 38, 531 (2013)

${ }^{13}$ J. Lindroos, M. Yli-Koski, A. Haarahiltunen, and H. Savin, Appl. Phys. Lett. 101, 232108 (2012).

${ }^{14}$ J. Lindroos, Y. Boulfrad, M. Yli-Koski, and H. Savin, J. Appl. Phys. 115, 154902 (2014).

${ }^{15}$ M. Boehringer, J. Hauber, S. Passefort, and K. Eason, J. Electrochem. Soc. 152, G1 (2005).

${ }^{16}$ Y. Boulfrad, J. Lindroos, M. Wagner, F. Wolny, M. Yli-Koski, and H. Savin, Appl. Phys. Lett. 105, 182108 (2014).

${ }^{17}$ K. Bothe and J. Schmidt, J. Appl. Phys. 99, 013701 (2006).

${ }^{18}$ M. B. Shabani, T. Yoshimi, and H. Abe, J. Electrochem. Soc. 143, 2025 (1996).

${ }^{19}$ W. Shockley and W. T. Read, Phys. Rev. 87, 835 (1952).

${ }^{20}$ R. N. Hall, Phys. Rev. 87, 387 (1952).

${ }^{21}$ M. Wilson, J. Lagowski, L. Jastrzebski, A. Savtchouk, and V. Faifer, AIP Conf. Proc. 550, 220 (2001).

${ }^{22}$ K. Bothe, R. Sinton, and J. Schmidt, Prog. Photovolt.: Res. Appl. 13, 287 (2005).

${ }^{23}$ H. Väinölä, E. Saarnilehto, M. Yli-Koski, A. Haarahiltunen, J. Sinkkonen, G. Berenyi, and T. Pavelka, Appl. Phys. Lett. 87, 032109 (2005).

${ }^{24}$ H. Amjadi, IEEE Trans. Dielectr. Electr. Insul. 7, 222 (2000).

${ }^{25}$ L. E. Black and K. R. McIntoch, IEEE Trans. Electron Devices 57, 1996 (2010).

${ }^{26} \mathrm{P}$. Wagner, H. Hage, H. Prigge, Th. Prescha, and J. Weber, in Semiconductor Silicon-1990, edited by H. R. Huff, K. G. Barraclough, and J.-I. Chikawa (Electrochemical Society, Pennington, NJ, 1990), p. 675.

${ }^{27}$ A. A. Istratov, C. Flink, H. Heislmair, E. R. Weber, and T. Heiser, Phys. Rev. Lett. 81, 1243 (1998).

${ }^{28}$ J. Lindroos, M. Yli-Koski, A. Haarahiltunen, M. C. Schubert, and H. Savin, Phys. Status Solidi RRL 7, 262 (2013). 